\title{
Buchbesprechungen
}

\section{Altertum und Mittelalter}

Catherine Wolff, Déserteurs et transfuges dans l'armée romaine à l'époque républicaine, Napoli: Jovene 2009, XXX, 453 S. (= Storia politica costituzionale e militare del mondo antico), EUR 35,00 [ISBN 978-88-243-1895-2]

Besprochen von Loretana de Libero: Hamburg, E-Mail: Libero@uni-potsdam.de

https://doi.org/10.1515/mgzs-2019-0020

Unerbittlich war der römische Feldherr Scipio während der Verhandlungen mit den eingeschlossenen Karthagern im Jahre 146 v.Chr. Den Überlebenden sicherte er zwar Leib und Leben zu, die römischen Überläufer aber hatten von ihm keine Gnade zu erwarten. In der römischen Republik wurden Soldaten, die ihren Posten verließen oder zum Feind überliefen, erbarmungslos verfolgt und grausam bestraft. Die berühmt-berüchtigte »disciplina militaris« sorgte durch Drill und Disziplin, durch Belohnungen und Bestrafungen dafür, dass die Bürgersoldaten Roms auch fernab vom eigenen Zuhause nicht von der Fahne gingen - oder eine solche Aktion zumindest bitter bereuen sollten.

Das Phänomen der Fahnenflucht hat vor allem seit den 1990er Jahren in der Geschichtswissenschaft größere Aufmerksamkeit erfahren. Mit »Roman Military Discipline« hat Sara Elise Phang 2008 erstmals für den Bereich der klassischen Altertumswissenschaften eine kulturhistorische Forschungsarbeit vorgelegt, die unter anderem auch diese komplexe Materie für die Zeit der späten Republik und des frühen Prinzipats behandelt. Bemerkenswert ist, dass sich bislang fast ausschließlich Althistorikerinnen mit dem Thema beschäftigten: Neben Sara Elise Phang sind etwa zu nennen Gabriele Wesch-Klein, Margarita Vallejo Girvés oder Catherine Wolff.

Die an der Universität von Avignon lehrende Alt- und Militärhistorikerin Catherine Wolff betrachtet in ihrer quellengesättigten Studie Desertion im Zeitalter der römischen Republik. Zunächst analysiert sie nachgerade erschöpfend die uns über die antike Terminologie geläufigen Kategorisierungen: Das römische Militärstrafrecht unterschied bekanntlich zwischen Fahnenflüchtigen, die sich dem Krieg und dem Militärdienst dauerhaft zu entziehen suchten (desertores), und solchen, die für eine gewisse Zeit eigenmächtig abwesend waren (emansores). Auch bei den Überläufern, den »transfugae«, lassen sich zwei Grundtypen ausmachen: den echten »Ueberläufer aus Leichtsinn oder Leidenschaft« (Ludwig Ramshorn) und den als Überläufer getarnten Spion oder »Innentäter «. Auf dieser Grundlage untersucht Wolff, wer im Einzelnen von der Fahne ging, welche Dienstgrade, ethnische und/oder soziale Herkunft in den Quellen 
genannt werden (S. XII-XXX; 5-66). Im zweiten Kapitel beleuchtet die Autorin die Gründe, welche die Soldaten Roms (aber auch anderer Armeen) bewogen haben, ihrer Truppe den Rücken zu kehren (S. 67-87). Die Quellen geben uns dazu nur wenig Hinweise. Motive waren, soweit erkennbar, psychischer, physischer und vor allem ökonomischer Art, was angesichts der Dauer und Härte des Kriegsdienstes nicht verwundern mag. Aber auch die personelle Loyalität gegenüber einem wechselfreudigen Heerführer bzw. Verbitterung oder Verzweiflung gegenüber einem vorgesetzten »Schinder« konnten ebenfalls ausschlaggebend gewesen sein. Rein politische oder moralisch-ethische Beweggründe sind für diese Zeit hingegen nicht überliefert. $\mathrm{Zu}$ diesem Komplex hätte noch die Arbeit von Lothar Wierschowski »Roma naturaliter bellicosa?« (Kriegsdienstverweigerung und Fahnenflucht im römischen Reich. In: Osnabrücker Jahrbuch Frieden und Wissenschaft, 4/1997, S. 131-153) herangezogen werden können. Im dritten Kapitel wird schließlich kurz dargelegt, auf welche Weise Soldaten "sich seitwärts in die Büsche schlugen« oder zum Feind überliefen (S. 89-102).

Einen weiten Raum nimmt im vierten Kapitel das wichtige, in der Rechtsgeschichte allerdings schon oft behandelte römische Militärstrafrecht ein (S. 103-174). Angesichts einer in der deutschen Althistorie gelegentlich erkennbaren Strömung, die antiken Gewaltphänomene doch eher harmonisierend zu betrachten, sind die langen Ausführungen zur Militärjustiz hier jedoch schon deshalb unbedingt geboten. Denn sie zeigen, dass allein mit Blick auf das römische Prinzip des unbedingten Gehorsams Desertieren und Überlaufen hart, zumeist mit einer grauenvollen Hinrichtungsart bestraft wurden. Überläufer galten als »hostes publici«, als Staatsfeinde. Römische Heerführer diktierten besiegten Gegnern einschlägige Klauseln in die Verträge, nach denen Überläufer ausgeliefert werden mussten. Schon aus Gründen der Abschreckung durften Fahnenflüchtige einer Strafverfolgung nicht entgehen. Was die Strafen im Einzelnen angeht, waren der Phantasie des Befehlshabers keine Grenzen gesetzt: So wurden in der römischen Republik Überläufer ausgepeitscht und enthauptet, wie Sklaven und Aufrührer gekreuzigt, verbrannt oder wilden Tieren vorgeworfen. In der Darstellung der Delikte und ihrer Ahndung hätte ich mir nur noch gewünscht, es wäre gegenüber anderen schweren Vergehen oder Verfehlungen im militärischen Bereich noch stärker differenziert worden. Feigheit vor dem Feind beispielsweise wurde gewöhnlich »milder«, bei ganzen Truppenteilen etwa mit einer »decimatio « bestraft (zu den Strafen immer noch Alfred Neumann in der RE Suppl. X [1965], S. 142-178 s.v. »disciplina militaris«).

Abschließend untersucht Wollf detailliert am Beispiel der Bundesgenossenund Bürgerkriege der ausgehenden Republik, wer warum desertierte bzw. überlief. Im Besonderen beleuchtet sie hierbei das Verhalten der einzelnen Feldherren 
unter den Bedingungen eines »failing state« und sich auflösender Bindungen und Loyalitäten römischer Legionäre und nichtrömischer Soldaten.

Letztlich ist festzuhalten, dass das überaus verdienst- wie gehaltvolle Werk von Catherine Wolff eine fundierte Grundlage für weitere Untersuchungen zu diesem faszinierenden Phänomen darstellt.

Die 900 römischen Überläufer von Karthago, denen Scipio keine Gnade widerfahren lassen wollte, suchten in ihrer Verzweiflung schließlich den Freitod in den brennenden Ruinen der Stadt. Die römische Seite mochte dies mit einer gewissen Genugtuung aufgenommen haben, denn dadurch entgingen diese "transfugae« ja gerade nicht ihrer gerechten Strafe, konnte doch das schändliche Überlaufen zum Feind auch durch den Feuertod geahndet werden. 